\title{
Germ cell Differentiation During Spermatogenesis, and Ultrastructural Characteristics of Mature Sperm in Male Phacosoma japonicus (Bivalvia: Veneridae)
}

\author{
Jin Hee Kim', Ee-Yung Chung ${ }^{2}$, Moon Sul Choi ${ }^{3}$ Ki-Young Lee ${ }^{3}$, IL-Ho Lee ${ }^{4}$ and \\ Won-Jae $\mathrm{Seo}^{2}$ \\ ${ }^{1}$ Korea Ocean \&Fisheries Institute, Busan 608-810, Korea \\ ${ }^{2}$ Korea Marine Environment \& Ecosystem Institute, Dive Korea, Bucheon 420-857, Korea \\ ${ }^{3}$ Department of Marine Biotechnology, Kunsan National University, Gunsan 573-701, Korea \\ ${ }^{4}$ Department of Fisheries Science, Graduate School, Kunsan National University, Gunsan 573-701, Korea
}

\begin{abstract}
Some characteristics of germ cell differntiations during spermiogenesis and mature sperm ultrastructure in male Phacosoma japonicus were investigated by transmission electron microscope observations. The morphology of the spermatozoon of this species has a primitive type and is similar to those of other species in the subclass Heterodonta. Morphologies of the sperm nucleus and the acrosome of this species are the cylindrical type and cap shape, respectively. The spermatozoon is approximately 45-50 $\mu \mathrm{m}$ in length, including a long curved sperm nucleus (about $3.70 \mu \mathrm{m}$ long with $45^{\circ}$ of the angle of the nucleus, an acrosome (about $0.55 \mu \mathrm{m}$ in length), and tail flagellum (about 42-47 $\mu \mathrm{m}$ ). The axoneme of the sperm tail shows a 9+2 structure. As some characteristics of the acrosomal vesicle structures, the basal and lateral parts of basal rings show electron opaque part (region), while the anterior apex part of the acrosomal vesicle shows electron lucent part (region). These characteristics of the acrosomal vesicle were found in the family Veneridae and other several families in the subclass Heterodonta. These common characteristics of the acrosomal vesicle in the subclass Heterodonta can be used for phylogenetic and systematic analysis as a taxonomic key or a significant tool. The number of mitochondria in the sperm midpiece of this species are four, as one of common characteristics appear in most species in the family Veneridae and other families in the subclass Heterodonta. However, exceptionally, only three species in Veneridae of the subclass Heterodonta contain 5 mitochondria. The number of mitochondria in the sperm midpiece can be used for the taxonomic analysis of the family or superfamily levels as a systematic key or tools.
\end{abstract}

Key words: Phacosoma japonicus, spermiogenesis, mature sperm ultrastructural characteristics

\section{INTRODUCTION}

Germ cell differentiations during Spermatogenesis and mature sperm ultrastructural features have been documented in many species of bivalve molluses using both light and transmission electron microscopy (Daniels et al., 1971; Franzén, 1970, 1983; Dorange

Received January 13, 2011; Revised January 31, 2011; Accepted March 4, 2011

Corresponding author: Ki-Young Lee

Tel: +82 (63) 469-1832 e-mail: leekiy@kusan.ac.kr

$1225-3480 / 24377$ and Le Pennec, 1989; Healy, 1989, 1995; Healy and Lester, 1991; Gaulejac et al., 1995; Eckelbarger et al., 1990, Eckelbarger and Davis, 1996; Chung and Ryou, 2000; Chung et al., 2007, 2010). It is well-known that spermatogenesis occurs through spermatogenic germ cell differentiations in acini of the testis. Therefore, above all, it is important to investigate the processes of germ cell differentiations by developmental stages during spermatogenesis to clarify the reproductive mechanism.

To date, previously there have been only a few studies on reproduction and ecology in Phacosoma japonicus, including aspects of maturation and 
spawning (Chung et al., 1997), and its distribution and ecology (Min et al., 2004). Although reproduction and ecology of this species have been investigated by some authors, little information is available on germ cell differentiations during spermatogenesis, and ultrastructural characteristics of mature sperm of this species. Therefore, it is important to study some characteristics of germ cell differentiations during spermatogenesis to clarify the reproductive mechanism by transmission electron microscope observation, and to investigate the ultrastructural features of mature spermatozoa.

In bivalve molluscs, in particular, sperm ultrastructure is considered a valuable tool in assessing taxonomic and phylogenetic problems within the Bivalvia (Bacetti, 1970; Daniels et al., 1971; Popham, 1979; Healy, 1989, 1995; Hodgson and Bernard, 1986; Eckelbarger et al., 1990, Eckelbarger and Davis,1996) and is especially useful when comparing closely related species (Popham, 1974; Popham, 1979). Thus sperm ultrastructures of bivalves are now widely used in taxonomic analysis (Healy, 1995; Chung et al., 2010).

It is well-known that acrosomal morphologies of sperms have been used to organize bivalve subclasses (Popham, 1979; Healy, 1989), the number of mitochondria in the sperm midpiece tends to be stable within any given family or superfamily. For that reason, it need to study acrosomal morphology of the sperm and the number of mitochondria in the sperm midpiece for taxonomic analysis of this species. For the study of taxonomic analysis of $P$. japonicus, which belongs to Veneridae in the subclass Heterodonta, acrosomal morphorlogy of mature sperm needs to compare their similarities with many species in other families of Heterodonta, and the number of mitochondria need to compare with many species in the families or superfamilies in Heterodonta. Information on sperm ultrastructure is sorely needed for this important clade of bivalves. Therefore, the pupose of this study is to describe germ cell differentiation during spermatogenesis with some special features of mature sperm ultrastructure, and to clarify the types of sperm nucleus and acrosome as well as the number of mitochondria in the sperm midpiece by phylogenetic and taxonomic analyses of $P$ japonicum.

\section{METHODS AND MATERIALS}

\section{Sampling}

A total of 65 male clams of $P$. japonicus were collected in the intertidal zone of Biin Bay, Chungcheongnam-do, Korea, from January to December, 2008. The clams were transported to the laboratory where they were maintained in seawater at $20^{\circ} \mathrm{C}$. The specimens were used for ultrastructural study of germ cells and mature spermatozoa by transmission electron microscopy.

\section{Ultrastructures of germ cells and mature sperm}

For transmission electron microscope observations, excised pieces of the gonads were cut into small pieces and fixed immediately in 2.5\% paraformaldehydeglutaraldehyde in $0.1 \mathrm{M}$ phosphate buffer solution $(\mathrm{pH}$ 7.4) for 2 hours at $4^{\circ} \mathrm{C}$. After prefixation, the specimens were washed several times in the buffer solution and then postfixed in a $1 \%$ osmium tetroxide solution in $0.2 \mathrm{M}$ phosphate buffer $\left(\mathrm{pH}\right.$ 7.4) for 1 hour at $4{ }^{\circ} \mathrm{C}$. Specimens then were dehydrated in increasing concentrations of ethanol, cleared in propylene oxide and embedded in an Epon-Araldite mixture. Ultrathin sections of Epon-embedded specimens were cut with glass knives on a Sorvall MT-2 microtome and LKB ultramicrotome at a thickness of about 80-100 nm. Tissue sections were mounted on collodion-coated copper grids, doubly stained with uranyl acetate followed by lead citrate, and observed with a JEM 100 CX-II (80-KV) electron microscope.

\section{RESULTS}

\section{Developmental stages of spermatogenesis}

In general, spermatogenesis occurs in acini in the testis and can be divided into four stages: (1) spermatogonia, (2) spermatocytes, (3) spermatids, and (4) spermatozoa. On the whole, the process of spermatogenesis of this species appears to be similar to those of other bivalve species.

\section{1) Spermatogonia}

Spermatogonia are present along the acinus wall 
relatively large germ cells (approximately 6.3 to 7.2 $\mu \mathrm{m}$ in diameter), irregularly shaped cells having little cytoplasm and a large spherical nucleus (about 3.5-3.9 $\mu \mathrm{m}$ in diameter) containing scattered chromatin materials. At this time, a number of mitochondria and vacuoles appear in the cytoplasm, while the cytoplasm of this cell is largely devoid of organelles (Fig. 1).

\section{2) Spermatocytes}

Two stages of spermatocyte development, presumed to be primary and secondary, appear in the acinus walls of some specimens. The spermatogonia differentiate into primary spermatocytes which resemble the former except for the larger diameter of their nuclei. Primary spermatocytes (approximately 5.4-6.6 $\mu \mathrm{m})$ are slightly smaller cells that are distinguished by nuclei (approximately 3.2-3.8 $\mu \mathrm{m}$ ) with more abundant and more darkly staining chromatins. At this time, synaptonemal complexes appear in the nucleus during the patchtene phase in the prophase of maturation division The primary spermatocytes differentiate into secondary spermatocytes by the secondary maturation division. At this time, the nucleolus is no longer prominent (Fig. 2).

\section{3) Spermatids}

The secondary spermatocyte is transformed into the spermatids by the secondary meiotic division (Fig. 2). For convenience, spermiogenesis has been classified arbitrarily into two stages: the early and late stages. In the early stage of spermiogenesis, spermatids (approximately $4.3-4.6 \mu \mathrm{m}$ in diameter) are oval in shape, and the nucleus is spherical and occupies the center of the cell. The nucleus (about 3.2-3.4 $\mu \mathrm{m}$ in diameter) contains scattered electron-dense granular heterochromatins, and the cytoplasm contains several mitochondria (Fig. 3). The morphology of the spermatid nucleus changes gradually during the differentiation of the spermatid. At this time, small granules are formed by the Golgi complex in the cytoplasm move to a position just in front of the nucleus, while mitochondria move to a position just behind the nucleus. After all, the morphologies of the spermatid nuclei were gradually elongated, and one or a few granules in the cytoplasm of the spermatid become a proacrosomal vesicle (Fig. 4). The proacrosomal vesicle migrates to the presumptive anterior end of the nucleus of spermatid, where they coalesce to form a single electron-dense vesicle. The mitochondria become reduced in number but increase in size by mitochondrial fusion. The larger mitochondria form a close association with the nucleus, however, the shape of the nucleus is modified and becomes greatly elongated. A proacrosomal vesicle becomes cone-like acrosomal vesicle on the nucleus (Fig. 5). Thereafter, a cone-like acrosomal vesicle becomes an acrosome. And then the acrosome lying on the sperm nucleus become cone in shape (Fig. 6). In the basal part of the nucleus, the mitochondria become reduced in number but increase in size by mitochondrial fusion. Posterior to the nucleus is the midpiece. This region consists of four spherical mitochondria surrounding a pair of triplet substructure centrioles. The cristae of each mitochondrion are randomly arranged (Fig. 7). Larger mitochondria form a close association with the nucleus and in many cases appear tightly apposed to the nuclear envelope. At this time, of the two centrioles lying in the midpiece of the spermatozoon, the two centrioles, at right angles, show the classic nine triplets of microtubles. The proximal centriole lies at $90^{\circ}$ relative to the distal centriole and sperm longitudinal axis, and is connected to a shallow invagination of the nucleus by a thin layer of dense material. The distal centriole is attached to the plasma membrane. The distal centriole lies parallel to the sperm longitudinal axis and forms the point of origin for flagellar axoneme (Fig. 7). In the late stage of spermiogenesis, the spermatid nucleus is long elongated, and the cytoplasm is greatly reduced, and so the rate of nucleo-cytoplasm is high. After the sperm nucleus (average $3.70 \mu \mathrm{m}$ long) is long elongated, an acrosomal vesicle is also gradually very elongated (average $0.52 \mu \mathrm{m}$ long). The acrosome is composed of electron-opaque part. In particular, the axial filaments are not found in the acrosomal lumen, while subacrosomal granular materials are present in the subacrosomal space between the anterior 

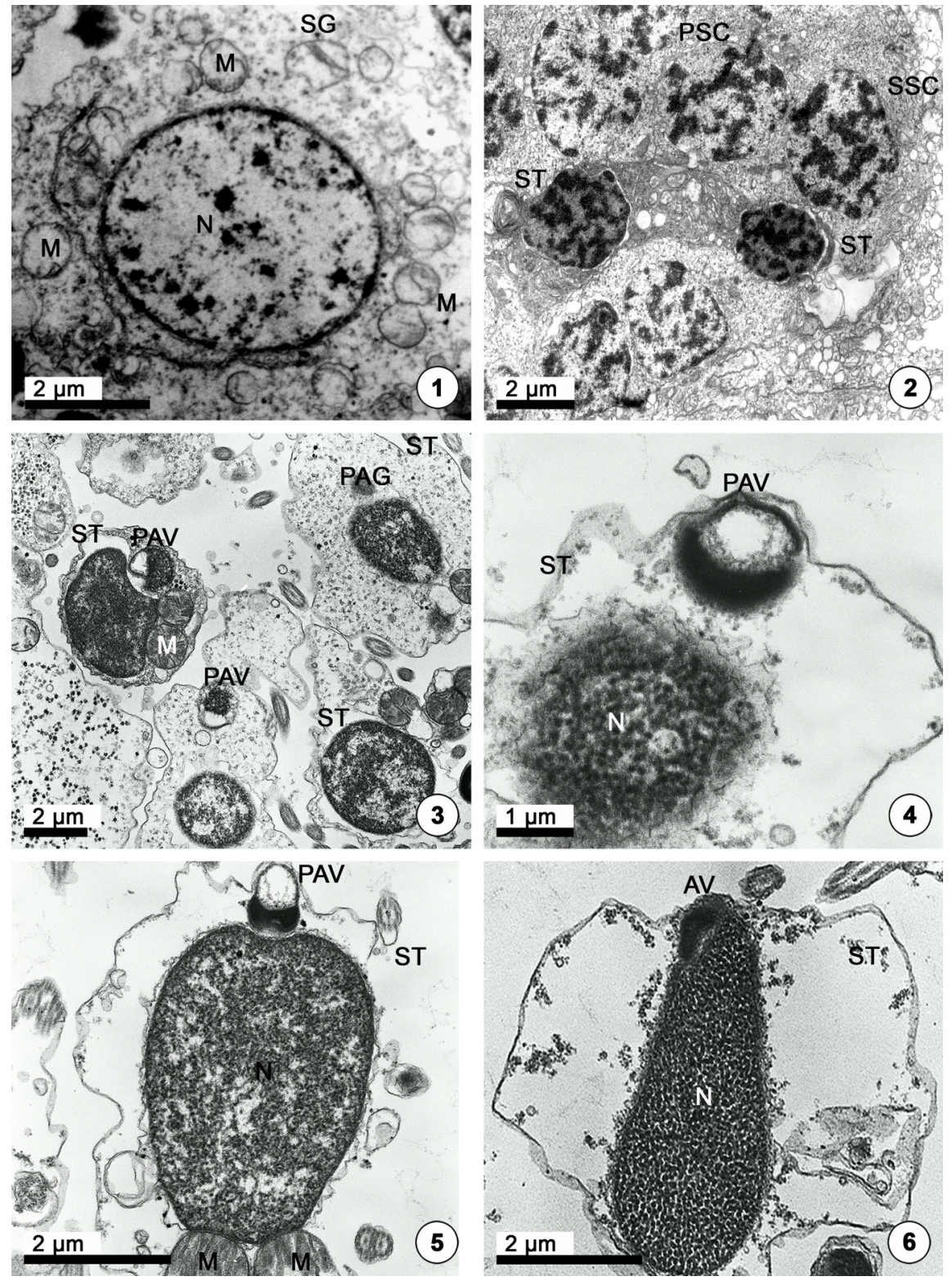

Fig. 1-6. Transmission electron micrographs of spermatogenesis and spermiogenesis in male Phacosoma japonicus. Fig. 1. A, spermatogonium (SG). Note a spermatogonium containing a nucleolus in the nucleus and several mitochondria (M) in the cytoplasm, Fig. 2. Primary spermatocytes (PSC), secondary spermatocytes (SSC) and spermatids (ST). Note several synaptonemal complexes in the nucleus of the primary spermatocytes (PSC) during the prophase of the primary maturation division, and heterochromatins in the nuclei of secondary spermatocytes (SSC) and spermatids (ST). Fig. 3. A spermatid (ST) in the early stage of differentiation during spermiogenesis. Note proacrosomal granules (PAG) and a proacrosomal vesicle (PAV) just before the nucleus (N) of the speratid. Fig. 4. A spermatid (ST) in the same stage of differentiation during spermiogenesis. Note proacrosomal vesicle (PAV) just before the nucleus $(\mathrm{N})$ of the speratid. Fig. 5 A spermatid (ST) and a proacrosomal vesicle (PAV) on the nucleus (N). Note a proacrosomal vesicle (PAV) attached to the spermatid nucleus and mitochondria (M) beneath the nucleus (N). Fig. 6. A spermatid and elongated nucleus (N). Note an acrosomal vesicle (AV) on the elongated nucleus $(\mathrm{N})$ of spermatid (ST). 


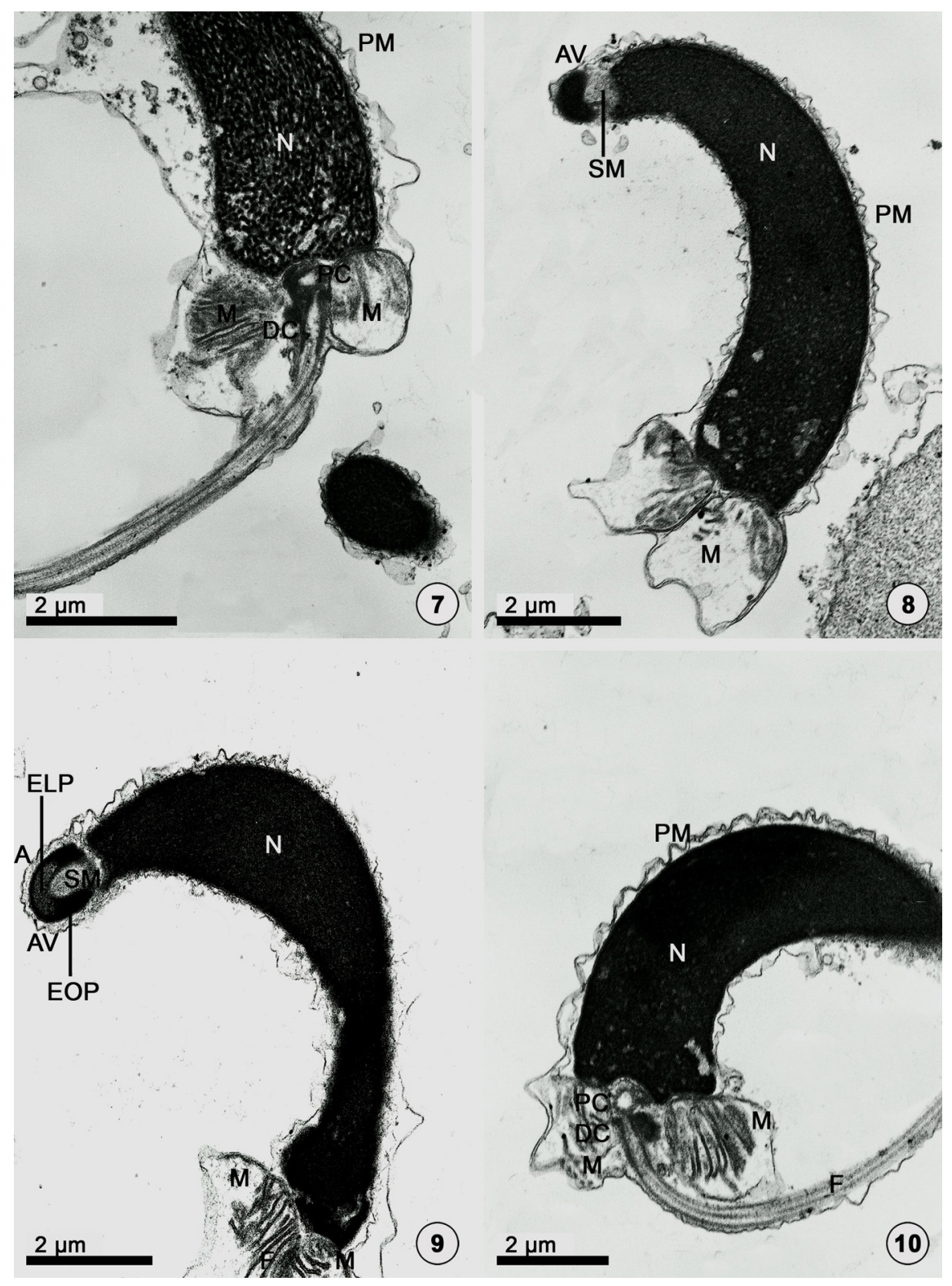

Fig. 7-10. Transmission electrone micrographs of the spermiogenesis in male Phacosoma japonicus. Fig. 7. Sperm midpiece beneath the curved nucleus (N) and a flagellum. Note the proximal centriole and distal centriole with spherical mitochondria beneath the posterior nuclear fossa and a tail flagellum. Fig. 8. Subacrosomal materials between the acrosomal vesicle and the nucleus. Note subacrosomal materials (SM) between the acrosomal vesicle (AV) and the anterior nuclear fossa of curved nucleus with the plasma membrane (PM), and large mitochondria (M) beneath posterior nuclear fossa. Fig. 9. A complete spermatozoon with the acrosomal vesicle, nucleus and large mitochondria (M). Note subacrosomal materials (SM) between basal and lateral parts of basal rings showing electron opaque parts (EOP), and the apex part showing electron lucent part (ELP) on the nucleus (N). Fig. 10. A complete spermatozoon with the head part, sperm midpiece, and tail part. Note the head part containig an acrosome and the curved nucleus $(\mathrm{N})$ with plasma membrane $(\mathrm{PM})$, the proximal $(\mathrm{PC})$ and distal centrioles (DC) surrounding large mitochondria $(M)$ in the sperm midpiece part, and a flagellum $(F)$ in the tail part. 

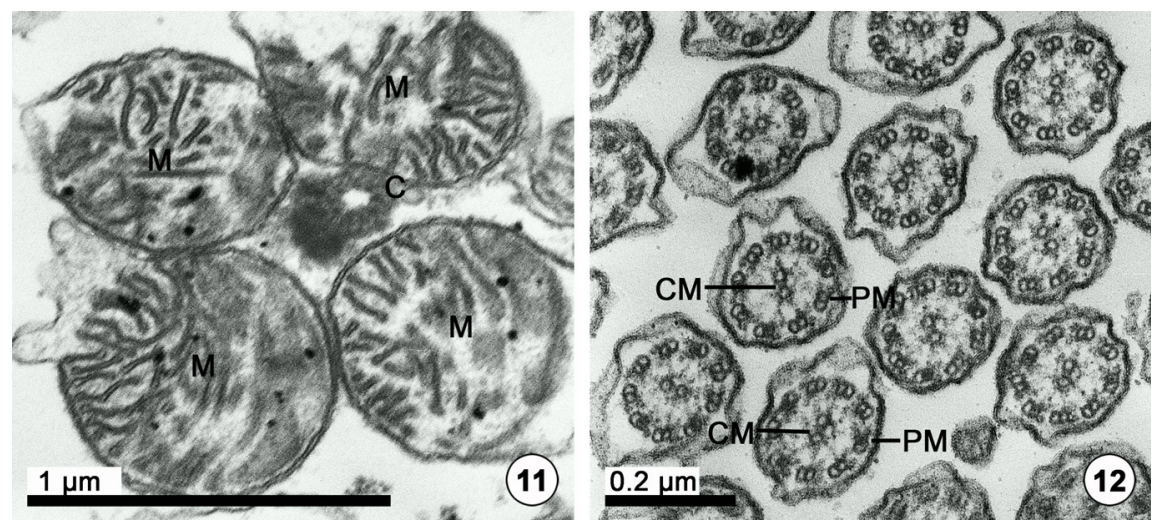

Fig. 11-12. Transmission electron micrographs of spermatozoa in male Phacosoma japonicus. Fig. 11. A cross sectioned sperm midpiece. Note a pair of centrioles surrouding with 4 mitochondria. Fig. 12. Cross sectioned sperm tail flagellum. Note the axoneme of the sperm tail flagellum showing a 9+2 structure (nine peripheral microtubules (PM) and a pair of central microtubules (CM)).

invaginated part of the nucleus and the acrosomal vesicle of the acrosome (Fig. 8). However, the axial filamet is not found in the subacrosomal materials in the acrosomal vesicle. At this time, the acrosomal vesicle is composed of well-developing basal rings, and the curved nucleus (angle of the nucleus: $45^{\circ}$ ) is covered with the plasma membran. The anterior nuclear fossa is exist in front of an acrosomal vesicle and the posterior nuclear fossa is present near the proxiamal centriole and distal centriole with some spherical mitochondria in the sperm midpiece (Fig. 8).

\section{4) Spermatozoa}

After spermiogenesis, differentiation of spermatozoon is completed. Sperm morphology is primitive, as found in most bivalve species that undergo external fertilization. As some characteristics of the acrosomal vesicle structures in an acrosome of this species, the basal and lateral parts of basal rings show electron opaque part (region), while the anterior apex part of the acrosomal vesicle shows electron lucent part (region, Figs. 9, 13). These characteristics of the acrosomal vesicle were found in the family Veneridae and other several families in the subclass Heterodonta.

Mature spermatozoa of this species measure approximately 45-50 $\mu \mathrm{m}$ long, and consist of conical acrosome positioned at the top of an elongated nucleus, a pair of centrioles surrounded by a ring of four spherical mitochondria, and a flagellum. The sperm head part is about $5.20 \mu \mathrm{m}$ long and comprises a long, electron-dense nucleus (about $3.70 \mu \mathrm{m}$ long), with the anterior nuclear fossa, and an acrosome. The acrosomal vesicle is about $0.55 \mu \mathrm{m}$ long, membrane-bound, and deeply invasinated. The acrosomal vesicle is a cone shape. The morphology of the sperm nucleus and the acrosomes of this species

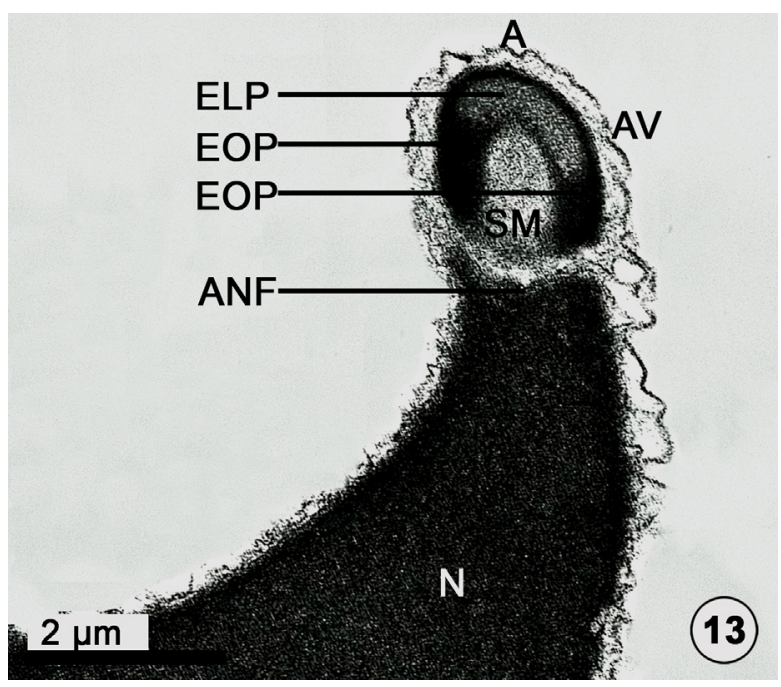

Fig. 13. A diagram of an acrosomal vesicle being composed of electron opaque part (EOP) and electron lucent part (ELP) in an acrosome on the anterior nuclear fossa of the curved nucleus in male Phacosoma japonicus. EOP: basal and lateral parts of the basal rings; ELP: the apex part of the basal ring. 
are of a curved cylindrical type (the angle of the nucleus: $45^{\circ}$ ) and a cone shape, respectively (Fig. 9). Irregular electreon-lucent lacunae are present in the nucleus (Fig. 10). Four spherical mitochondria with well-defined cristae occur near the posterior nuclear fossa of the nucleus (Fig. 11). However, the axial filaments or an axial rod and satelite fibres are not found in the ultrastructures of mature spermatozoa of this species. A cross-sectioned tail flagellum shows that the axoneme is composed of a classic 9+2 microtubular substructure (nine peripheral doublets surrounding a central pair of singlet microtubules) enclosed by a plasma membrane (Fig. 12).

\section{DISCUSSION}

\section{Spermatogenesis}

The testis of $P$. japonicus (Veneridae) is composed of a number of acini, spermatogenesis occurs in acini of the testis. The processes of germ cell differentiations and mature sperm ultrastucture of this species were similar to those in the species in bivalves (Chung et al., 2010). Therefore, the processes of spermatogenesis of bivalves was similar to those in the species in bivalves (Sakker, 1984; Bernard \& Hodgson, 1985; Chung, 2006; Chung et al., 2007, Kim et al., 2010a,b).

Spermatogonia were multiplicated by the mitotic division and developed into the primary spermatocytes containing electron dense scattered chromatins in the nucleus. In this study, synaptonemal complexes appeared among scattered chromatins in the patchtene stage of the prophase during the first maturation division in the nucleus of the primary spermatocyte. Therefore, it shows a characteristics of the primary spermatocytes. Although it is hard to distinguish the species according to some characteristics of early deveopmental stages of germ cells such as spermatogonia and spermatocytes, the concentration degree and morphology of chromatins will be an important factor to determine the type of the nucleus in the course of spermiogenesis from spermatids to spermatozoa. During spermiogenesis, according to concentration degree of chromatins in the spermatid nucleus, the morphology of the nucleus remarkablely changed into the anterior and posterior elongations or right and left extententions.

Yasuzumi (1974) reported that the nuclei of spermatids can be classified into three morphological types according to the concentration morphology and degree of chromatins in the nuclei of spermatids: (1) granular type, (2) fibrous type, and (3) layer type. However, in case of bivalves, it was a granular type in the early stage of chromatin concentrations, however, as the concentration of chromatins progresses, it was changed to be the fibrous type. The nuclear types are determined according to the concentration and elongation degree of chromatins. Kim (2001) reported that the nuclear morphology of the species having wide nucleus from side to side (Ostreidae, Mytilidae, etc.) and that of the elongated species back and fourth (Veneridae, Pectinidae, Corbiculidae, $M y a$ arenaria, Panopea japonica, etc.) is elongated with the concentration of fibrous chromatins. Thus, it is assumed that nuclear morphology is determined according to concentration degree and morphology of chromatins.

The acrosome is formed by various granular secreations secreted by the Golgi complex (Longo and Dornfeld, 1967; Sastry, 1979). In Mytilus coruscus, several small proacrosomal vesicle are formed by the Golgi complexes, and these vesicles were mixed with each other in the acrosomal vesicle during spermiogenesis (Kim et al., 2010a).

In P. yedoensis, after several granules were formed by the Golgi complexes in the early stage of spermiogenesis, a proacrosomal vesicle (high electron dense vesicular granules) was formed from a mixture of these granules.

In general, morphologies of proacrosomal vesicles showed some different speciality with the species, therefore, it is assumed that proacrosomal vesicles are formed in different course of most bivalves.

\section{Morphology and ultrastructure of mature spermatozoon}

In general, as a matter of convenience, the morphology of the spermatozooon of bivalve species can be divided into five types: (1) primitive type, (2) modified type, (3) biflagellate type, (4) biflagellate type, and (5) aflagellate type (Verdonk et al., 1983). Most bivalves belong to the primitive type, sperm 
ultrastructures are composed of three parts: (1) head, (2) midpiece, and (3) tail flagellum parts.

In the present study, the morphology of the spermatozoon of $P$. japonicum has a primitive type and is similar to those of other species in the subclass Heterodonta. The morphologies of the sperm nucleus and the acrosomal vesicle of this species are the cylindrical type and cap shape, respectively. Beside them, mature spermatozoa of this species contain subacrosomal material (embedded in a granular matrix), an elongated curved nucleus showing invaginated anteriorly, two tripletet substructure centrioles surrounded by four spherical mitochondria.

The spermatozoon is approximately $45-50 \mu \mathrm{m}$ in length including a long sperm nucleus (about $3.70 \mu$ $\mathrm{m}$ in length), an acrosome (about $0.45 \mu \mathrm{m}$ in length), and tail flagellum (about 42-47 $\mu \mathrm{m}$ ). 1983).

Ultrastructural characteristics of mature spermatozoa of this species showed somewhat different characteristics in many families in the subclass Heterodonta (Kim, 2001; Chung et al., 2010).

\section{Phylogenetic and taxonomic implicatios of mature spermatozoon ultrastructure}

Sperm ultrastructure has long been viewed as a tool in assesssing taxonomic problems and phylogenic relationship in the Metazoa through the use of spermiocladistic analysis (Jamieson, 1991; Healy, 1989, 1995). In this study, $P$. japonicus belongs to external fertilization species and the type of spermatozoa is the primitive type. Many species of Vemeridae in the subclass Heterodonta have three kinds of sperm nuclear types (cylinderical type) according to the angle of curved sperm nucleus: (1) no curved nuclear type (angle of the nucleus: $0^{\circ}$ ), (2) slightly curved nuclear type (angle of the curved sperm nucleus: $5^{\circ}-10^{\circ}$ ), and (3) largely curved sperm nuclear type (angle of the curved nucleus: 15-80 ${ }^{\circ}$.

Of them, Protothaca jedoensis $\left(0^{\circ}\right)$ belongs to no curved nuclear type, and three kinds of species (e.g. Gomphina veneriformis $\left(5^{\circ}\right)$, Meretrix lusoria $\left(10^{\circ}\right)$, Cyclina sinensis $\left(10^{\circ}\right)$ ) to the slightly curved nuclear type, and four kinds of species (e.g. Saxidomus purpuratus $\left(15^{\circ}\right)$, Ruditapes philippinarum $\left(25^{\circ}\right)$,
Mercenaria stimpsoni $\left(80^{\circ}\right)$ ) to the largely curved nuclear type. In particular, the nuclear type of $P$. japonicus belongs to largely curved nuclear type because the angle of the curved sperm nucleus is $45^{\circ}$. Thus, the angle of the sperm nuclear types vary with the species in Veneridae of Subclass Heterodonta.

Regarding the sizes of sperm nuclei (lengths) in the species of Veneridae in Subclass Heterodonta, Kim (2001) described that lengths of nuclei varied with the species of Veneridae: Meretrix lusoria is $1.49 \mu \mathrm{m}$, Cyclina sinensis $2.13 \mu \mathrm{m}$, and G. veneriformis $7.80 \mu$ $\mathrm{m}$. Therefore, it is assumed that sperm nuclei could not be used for the taxonomical key because the sizes of sperm nuclei vary with the species (Healy, 1995).

However, Healy (1995) stated that acrosomal morphologies of sperm ultrastructures of bivalves can be used for systematical analysis. Recently, Popham (1979) stated that morphological characteristics of the acrosomes of sperms can be used for the composition of the subclass. Healy (1989) stated acrosomal morphology of each species in the subclass shows an unique characteristics and reported some differences between Subclasses.

Popham (1979) reported some differences according to the morphologies and positions of sperm acrosomes of the species in 5 subclasses of bivalves. Hodgson and Bernard (1986) reported that sperm acrosomes can be classified into 5 subclasses according to morphologies of acrosomal vesicles and described some characteristics of the families of the subclass. Systematically, the family Veneridae belongs to the subclass Heterodonta. In this study, as shown in Fig. 13, acrosomal morphologies of species in all families of Subclass Heterodonta were mostly clindrical type or cap-like in shape. This point is one of common structural characteristics of the acrosomal vesicle.

In the acrosomal vesicle of spermatozoa of $P$. japonicus, the basal and lateral parts (regions) of the basal rings showed electron opaque part (region), while the anterior parts of the apex part of the acrosomal vesicle showed electron lucent part (region). Accordingly, these phenomena of this species showed remarkably similar patterns to various kinds of species of Veneridae, Mactridae, Tellinidae, 
Solenidae, Myidae, Hiatellidae in the subclass Heterodonta. Therefore, this species showed a typical characteristics of the subclass Heterodonta. In particular, in the acrosomes of species of the family of Veneridae, Mactridae, Solenidae in the subclass Hetrodonta, the anterior apex parts of acrosomal vesicles were very thin, and the boundaries of the inner and outer membranes were closely attached and acrosomal vesicles in acrosomes showed the cone types or cap-like shapes, as shown in common characteristics of the subclass Heterodonta. Hodgson and Bernard (1986) reported that in case of the subclass Pteriormorphia, the morphology of sperm acrosomal vesicles shows the same cone shape, as shown in the subclass Hetrodonta. However, it is a common characteristics of the species in the families of the subclass Pteriormorphia that all parts of acrosomal vesicles are composed of electron opaque parts (regions), unlikely the subclass Heterodonta showing electron opaque parts at the basal and lateral parts of basal rings and electron lucent part (region) at the anterior apex part. Therefore, $P$ japonicus showed a common characteristics of the subclass Heterodonta.

Of sperm ultrastructures, the axial filament or axial rod are present in the subacrosomal granular materials of the acrosomal vesicles in the acrosomes of several species of the subclass Heterodonta and Pteriormorphia. However, in spermatozoa of some species, it is hard to find their ultrastructures the subacrosomal granular materials in the space of acrosomal vesicles or they did not find in mature sperm ultrastructures because their spermatozoa have not their structure in many species of families in the subclass Heterodonta and Pteriormorphia. Thus, appearances of the axial filament and axial rod varied with the species of families in subclasses (Kim et al., 2010a; Chung et al., 2010).

To date, the axial filament in the subacrosomal granular materials have been only found in a few species of Veneridae (Kim, 2001; Chung et al., 2010) and Corbiculidae (Kim, 2001) in subclass Heterodonta, while in general, it was not found in the subacrosomal granular materials of sperm ultrastructure in subclass
Pteriormorphia, In addition, regarding the axial rod in the subacrosomal granular materials of the acrosomal vesicle, it was only found in a few species of Osteidae and Mytilidae in the subclass Pteriormorphia (Kim, 2001; Kim et al., 2010a). In this study, the axial filament was not found in the subacrosomal granular materials. P. japonicus belongs to Veneridae such as Saxidomus purpuratus, Meretrix lusoria and $P$. jedoensia in subclass Heterodonta. However, the acrosomal vesicles of $R$. philippinarum (Kim, 2001) and G. veneriformis in Veneridae contained the axial filament in the subacrosomal granular materials (Chung et al., 2010).

Regarding the satellite fibres of sperm ultrastructure, it was reported that they were not found in all species in Veneridae, Mactridae, Corbiculidae, Myidae, Solenidae, Tellinidae and Hiatellidae of the subclass Hetrerodonta, while they were found in many species of Ostreidae, Arcidae, Mytilidae and Pectinidae of the subclass Pteriormorphia except for Pinnidae and Pteridae. In this study, the satellite fibres of sperm ultrastructure of this species was not found because Veneridae species has not this structure, unlikely spermatozoa of Ostreidae species of the subclass Pteriomorphia.

Hodgson and Bernard (1986) and Healy (1989) stated that the number of mitochondria in the sperm midpiece tends to be stale within any family or superfamily varying from a maximum of 14 in the mytilord Modiolus difficilis (Drozdov and Reunov, 1986) to a minimum of 4 (Healy, 1989, 1995). Based on the results reported by some authors (Chung \& Ryou, 2000; Kim, 2001; Chung et al., 2006), the number of mitochondria at the midpiece of sperm of bivalves were four in Veneridae, Solenidae, Corbiculidae in subclass Heterodonta and Ostreidae in subclass Pteriomorphia, while those of mitochondria were five in Arcidae, Mytilidae in subclass Pteriomorphia and some species of Veneridae (Saxidomus purpuratus, Meretrix lusoria, Cyclina sinensis) and Atrina pinnata japonica.

Healy (1989) reported that the number of mitochondria at the middpiece of sperm showed unconstant and irregular characteristics in the level 
of subclass, however showed stable a constant characteristics under the level of family or in superfamily. Accordingly, the results of the number of the mitochondria are coincided with that reported by Healy (1989). In this study, the number of mitochondria at the midpiece of the spermatozoon are four (common to many bivalve families), and satellite fibres are not found in the family Veneridae. Judging from the results on the ultrastructure of mature spermatozoon, it is supposed that this species belongs to family Veneridae and subclass Heterodonta because the axial rod in the acrosomal vesicle or satellite fibres in the sperm midpieceare were not found in the sperm ultrastructure, unlikely the structures of the acrosomal vesicle of Ostreidae sperm in the subclass Pteriomorphia.

On the whole, appearances of the axial filament or axial rod, and satellite fibres varied with the species of families in Subclasses (Kim et al., 2010b; Chung et al., 2010).

\section{ACKNOWLEDGEMENTS}

The authors are grateful to Dr. Tae Hwan Lee, the University Of Michigan for helpful comments on the manuscript. This research was supported in part by the funds from the Research Projects of the Fisheries Science Institute, Kunsan National University.

\section{REFERENCES}

Bernard, R.T.F. and Hodgson, A.N. (1985) The fine structure of the sperm and spermatid differentiation in the brown mussel Perna perna. South Africa Journal of Zoology, 20: 5-9.

Baccetti B (1970) The spermatozoon of Athropoda. IX. The sperm cell as an index thropod phylogenesis. p. 169-181.

Chung, E.Y., Kim, B.G. and Seo Y.H. (1997) Maturation and spawning of the Japanese dosinia, Dosinorbis (Phacosoma) japonicus in the coastal waters of western Korea. The Korean Journal of Malacology, 13: $43-54$.

Chung, E.Y. and Ryou, D.K. (2000) Gametogenesis and sexual maturation of the surf clam Mactra venerifermis on the west coast of Korea. Malacologia, 42: 149-163.

Chung, E.Y. (2006) Ultrastructure of germ cells during spermatogenesis and the reproductive cycle in male Meretrix petechialis on the west coast of Korea.
Korean Journal of Malacology, 22: 115-124.

Chung, E.Y., Kim, H.J., Kim, J.B. and Lee, C.H. (2006) Changes in biochemical components of several tissue in Solen grandis, in relation to gonad developmental phases. Korean Journal of Malacology, 22: 27-38.

Chung, E.Y., Kim, E.J. and Park, G.M. (2007) Spermatogenesis and sexual maturation in male Mactra chinensis (Bivalvia: Mactridae) of Korea. Integrative Bioscience, 11: 227-234.

Chung, E.Y., Chung, C.H., Kim, J.H., Park, S.W. and Park, K.H. (2010) Ultrastructures of germ cells and the accessory cells during spermatogenesis in male Gomphina veneriformis (Bivalvia: Veneridae) on the East Sea of Korea. Korean Journal of Malacology, 26: $51-62$.

Daniels, E.W., Longwell, A.C., Mc Niff, J.M. and Wolfgang, R.W. (1971) A reinvestigation of the ultrastructure of the spermatozoa from the american oyster Crassostrea virginica. Trans American Microscopy Society, 90: 275-282.

Dorange, G. and Le Pennec, M.L. (1989) Ultrastructural characteristics of spermato- genesis in Pecten maximus (Mollusca, Bivalvia). Invertebrate Reproduction Development, 15: 109-117.

Drozdov, T.A. and Reunov, A.A. (1986) Spermatogenesis and the sperm ultrastructure in the mussel. Modiolus difficillis. Tsitologiia, 28: 1069-1074.

Eckelbarger, K.J., Bieler, R., and Mikkelsen, P.M. (1990) ltrastructure of sperm development and mature sperm morphology in three species of commensal bivalves (Mollusca: Galeommatoidea). Journal of Morphology, 205: 63-75.

Eckelbarger, K.J. and Davis, C.V. (1996) Ultrastructure of the gonad and gametogenesis in the eastern oyster, Crassostrea virginica. II. Testis and spermatogenesis. Marine Biology, 127: 89-96.

Franzén, §. (1970) Phylogenetic aspects of the mophology spermatozoa and spermiogenesis. In; Baccetti B (ed) "Comparative spermatology.". Accademia Nationale Dei Lincei, Rome, pp. 573.

Franzén, A. (1983) Ultrastructural studies of spermatozoa in three bivalve species with notes on evolution of elongated sperm nucleus in primitive spermatozoa. Gamete Research, 7: 199-214.

Gaulejac, de J., Jenry, M. and Vicente, N. (1995) An ultrastructural study of gametogenesis of the marine bivalve Pinna nobilis (Linnaeus, 1758). II. Spermatogenesis. Journal of Molluscan Studies, 61: 393-403.

Healy, J.M. (1989) Spermiogenesis and spermatozoa in the relict bivalve genus Neotrigonia: relevance to trigonioid relationships, particularly Unionoidea. Marine Biology, 103: 75-85.

Healy, J.M. (1995) Sperm ultrastructure in the marine bivalve families Carditidae and Crassatellidae and and its bearing on unification of the Crasssatelloidea with the Carditoidea. . Zoological 
Science, 24: 1-28.

Healy, J.M. and Lester, R.J.G. (1991) Sperm ultrastructure in the Australian oyster Saccostrea commercialis (Iredale and Roughley) (Bivalvia: Ostreidea). Journal of Molluscan Studies, 57: 219-224.

Hodgson, A.N. and Bernard, R.T.F. (1986) Ultrastructure of the sperm and spermatogenesis of three species of Mytilidae (Mollusca, Bivalvia). Gamete Research. 15: $123-135$.

Jamieson, B.G.M. (1991) Fish evolution and systematics: evidence from spermatozoa. Cambridge University Press, Cambridge, pp.181-194.

Kim, J.H. (2001) Spermatogenesis and comparative ultrastructure of spermatozoa in several species of Korean economic bivalves (13 families, 34 species). Pukyung National University $161 \mathrm{pp}$.

Kim, J.H., Chung, E.Y., Choi, K.H., Park, K.H. and Park, S.W. (2010a) Ultrastructure of germ cells during spermatogenesis and some characteristics of sperm morphology in Male Mytilus coruscus (Bivalvia: Mytilidae) on the west coast of Korea. Korean Journal of Malacology, 26: 33-43.

Kim, J.H., Chung, E.Y., Choi, K.H., Lee, K.Y. and Choi, M.S. (2010b) Ultrastructure of the testis and germ cell development during spermatogenesis in male Crassostrea gigas (Bivalvia: Ostreidae) in western Korea. Korean Journal of Malacology, 26: 235-244.

Longo, E.J. and Dornfeld, E.J. (1967) The fine structure of spermaid differentiation in the mussel, Mytilus edulis, L. Ultrastructural Research, 20: 462-480.

Min, D.K., Lee, J.S., Ko. D.B. and Je, J.G. (2004) Mollusks in Korea. Hanguel Graphics. 566pp.

Popham, J.D. (1974) Comparative morphometrics of the acrosomes of the sperms of externally and internally fertilizing sperms of the sperms of the shipworms (Teredinidae, Bivalvia, Mollusca). Cell Tissue Research, 150: 291-297.

Popham, J.D. (1979) Comparative spermatozoon morphology and bivalve phylogeny. Malacological Review, 12: 1-20.

Sakker, E.R. (1984) Sperm morphology, spermatogenesis and spermiogenesis of three species of chitons (Mollusca, Polyplacophora). Zoomorphology, 104: 111-121.

Sastry, A.N. (1979) Pelecypoda excluding Ostreidae. In Giese AC, Pearse JS eds. "Reproduction of Marine Invertebrates". Vol 5, New York. Academic Press pp. 113-292.

Verdonk, N.H., Van Den Biggelaar, J.A.M. and Tompa A.S. (1983) The Mollusca. Vol. 3. Development. Academic Press, New York, pp 48.

Yasuzumi, G. (1974) Electron microscope studies on spermatogenesis in various species. International Review Cytology, 37: 53-119. 